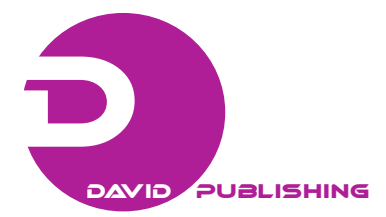

\title{
Liquid-Phase Synthesis of Adipic Acid Using Keggin-Type Phosphomolybdates Catalysts
}

\author{
Tassadit Mazari $^{1,2}$, Sihem Benadji ${ }^{1}$, Adlane Tahar $^{1}$, Leila Dermeche ${ }^{1,2}$ and Chérifa Rabia ${ }^{1}$ \\ 1. Natural Gas Chemistry Laboratory, Chemistry Faculty, University of Sciences and Technology Houari Boumediène (USTHB), \\ El-Alia, Bab-Ezzouar 16111, Algeria \\ 2. Chemistry Department, Sciences Faculty, Univeristy of Mouloud Mammeri, Tizi Ouzou 15000, Algeria
}

Received: November 15, 2012 / Accepted: December 06, 2012 / Published: March 25, 2013.

\begin{abstract}
Adipic acid was synthesized from oxidation of cyclohexanol (-ol), cyclohexanone (-one) or a mixture of cyclohexanol and cyclohexanone (-ol/-one) in the presence of hydrogen peroxide in liquid-phase using Keggin-type heteropolysalts (HPS) of formula $\mathrm{M}_{\mathrm{x}} \mathrm{PMo}_{12} \mathrm{O}_{40}$ (noted $\mathrm{MPMo}_{12}$ with $\mathrm{M}: \mathrm{H}, \mathrm{Ni}, \mathrm{Co}, \mathrm{Fe}$ ) as catalysts. The HPS were characterized by elementary analysis, Fourier transform infrared spectroscopy (FT-IR), UV-visible spectroscopies, X-ray (XR) diffraction and (Brunauer, Emmett and Teller) BET method. Among the HPSs studied, FePMo $\mathrm{Mo}_{12}$ shows no catalytic activity while Co-based HPS exhibits the highest yield to adipic acid for whole subtracts (-ol, -one and -ol/-one).
\end{abstract}

Key words: Adipic acid, oxidation, cyclohexanol, cyclohexanone, keggin compounds, hydrogen peroxide.

\section{Introduction}

Adipic acid (AA) is a valuable raw material used in the production of nylon- 6 , 6, fibers, plasticizers, and food additives. Its industrial production is realized from the oxidation of a cyclohexanol/cyclohexanone mixture over $\mathrm{Cu} / \mathrm{V}$ catalyst with an $\mathrm{HNO}_{3}$ excess (50\%-60\%) [1-3]. The reached yield is about $95 \%$ with glutaric (GA) and succinic (SA) acids as by-products. This process also leads to the nitrogen oxides $\left(\mathrm{NO}_{\mathrm{x}}\right)$ formation. Among them, $\mathrm{N}_{2} \mathrm{O}$ that participates in the ozone layer destruction and greenhouse effect is produced with an equivalent proportion than that of adipic acid.

Due to these drawbacks and developing an environmentally more friendly, several methods have been proposed in the literature for the adipic acid synthesis. The objective of the researches is to substitute nitric acid, corrosive and pollutant agent, by an oxidant that can enter in the field of "green

Corresponding author: Chérifa Rabia, professor, research fields: preparation and characterization of inorganic materials, catalysis. E-mail: c_rabia@yahoo.fr and crabia@usthb.dz. chemistry". Molecular oxygen and hydrogen peroxide are the preferred oxidants. On the other hand, hydrogen peroxide, $\mathrm{H}_{2} \mathrm{O}_{2}$, leads only to water as by-product in oxidative reactions. The catalysts studied are generally based on transition elements as $\mathrm{Co}, \mathrm{Mn}, \mathrm{W}$ and Mo.

Thus, it was reported that $\mathrm{Co} / \mathrm{Mn}$ cluster complexes exhibit high catalytic activity and selectivity for the aerial oxidation, in the homogeneous liquid phase, of cyclohexane, cyclohexanol or cyclohexanone to adipic acid. The cluster complexes are more active than the individual $\mathrm{Co}$ and $\mathrm{Mn}$ acetates. The adipic acid yields are comparable to those in the current processes using $\mathrm{HNO}_{3}$ [4]. Adipic acid synthesis catalyzed by surfactant-type peroxotungstates and peroxomolybdates from the cyclohexene and 1,2-cyclohexanediol oxidation by hydrogen peroxide without organic solvent showed that peroxotungstate catalysts exhibited higher activities than peroxomolybdates catalysts. However, moderate yields to adipic acid were obtained in the cyclohexanol and cyclohexanone oxidation [5].

Keggin-type polyoxometalates were also tested in 
the adipic acid synthesis. Thus, cyclohexanol oxidation to cyclohexanone and further oxidation to adipic acid were studied using tetrabutylammonium salts of $\mathrm{P} / \mathrm{Mo}$ and $\mathrm{P} / \mathrm{W}$ Keggin-type heteropolyacids (HPAs). It was found that HPAs react catalytically in the presence of aqueous hydrogen peroxide whereas; they react only stoichiometrically without it. Since, hydrogen peroxide converts the HPA reduced-form (blue) produced by the substrate oxidation, to the oxidized-form (yellow). $\mathrm{H}_{2} \mathrm{O}_{2}$ plays the role of a promoter or a reoxidizing agent during the subtract oxidation by the HPA [6].

The adipic acid synthesis from cyclohexene and hydrogen peroxide catalyzed by complexes derived from heteropolyacid $(\mathrm{P} / \mathrm{Mo}, \mathrm{P} / \mathrm{W})$ and glycine led to high yield (95\%). It was found that $\mathrm{P} / \mathrm{W}$ based catalyst exhibited higher activities than P/Mo based catalyst [7].

The cyclohexanone oxidation to adipic acid catalysed by $\mathrm{H}_{3+x} \mathrm{PMo}_{12-x} \mathrm{~V}_{x} \mathrm{O}_{40} \quad(x=1$ and 2$)$ heteropolyacids, using air as oxidant, was studied by $\mathrm{F}$. Cavani, et al.. [8]. It was found that when the reaction is conducted in the presence of the water only, it proceeds via a redox mechanism, in that the step of reoxidation of reduced HPA by oxygen is the limiting rate. However, when the reaction was carried out with an acetic acid as co-solvent, a radical-chain autoxidation mechanism prevailed. The selectivity to adipic acid was affected by both the reaction mechanism and the cyclohexanone conversion, due to the presence of a complex reaction network.

In the present work, we focused on the application of Keggin-type heteropolysalts (HPSs) as catalysts for the liquid-phase oxidation of cyclohexanol (-ol), cyclohexanone (-one) and cyclohexanol $(50 \%)$ and cyclohexanone (50\%) (-ol/-one) mixture to adipic acid in the presence of hydrogen peroxide $(30 \%)$ under solvent-free conditions. Polyoxometalates are known to have tunable acidic and redox properties that can be controlled by changing the constituent elements in function of the reaction requirements. Their catalytic performance is greatly enhanced by the transition metals incorporation in the oxidation processes. Our choice was made on a series of soluble heteropolysalts of $\mathrm{M}_{x} \mathrm{PMo}_{12} \mathrm{O}_{40}$ formula noted $\mathrm{MPMo}_{12}$ with $\mathrm{M}: \mathrm{Ni}, \mathrm{Co}$, $\mathrm{Fe}(\mathrm{x}=1$ for $\mathrm{Fe}$ and 1.5 for Ni and $\mathrm{Co})$ together with $\mathrm{H}_{3} \mathrm{PMo}_{12} \mathrm{O}_{40}$. HPSs were characterized by BET and XR diffraction method, by FT-IR, and UV-Vis spectroscopies and tested in adipic acid synthesis. The effects of HPS mass and the reaction mixture stirring rate on the catalytic properties were also studied.

\section{Experiments}

\subsection{Catalysts Preparation}

$\mathrm{H}_{3} \mathrm{PMo}_{12} \mathrm{O}_{40}$ was prepared according to a classical method and $\mathrm{M}_{x} \mathrm{PMo}_{12} \mathrm{O}_{40}(\mathrm{M}: \mathrm{Fe}, \mathrm{Ni}, \mathrm{Co}$ and $x=1$ or $1.5)$ heteropolysalts by a cationic exchange method in two steps. First, $\mathrm{Ba}_{x} \mathrm{PMo}_{12} \mathrm{O}_{40}$ was synthesized by addition of $\mathrm{Ba}(\mathrm{OH})_{2}$ to an aqueous solution of $\mathrm{H}_{3} \mathrm{PMo}_{12} \mathrm{O}_{40}$ in stoichiometric ratios, followed by precipitating of $\mathrm{BaSO}_{4}$ using transition metal sulfate with cationic exchange between $\mathrm{H}_{3-2 x} \mathrm{Ba}_{x} \mathrm{PMo}_{12} \mathrm{O}_{40}$ and $\mathrm{MSO}_{4}$ according to Eqs. (1) and (2). After filtration, the resulting heteropolysalt solution was evaporated to dryness at $50{ }^{\circ} \mathrm{C}$.

$$
\begin{aligned}
\mathrm{H}_{3} \mathrm{PMo}_{12} \mathrm{O}_{40}+x \mathrm{Ba}(\mathrm{OH})_{2} & \rightarrow \mathrm{H}_{3-2 x} \mathrm{Ba}_{x} \mathrm{PMo}_{12} \mathrm{O}_{40} \\
& +2 x \mathrm{H}_{2} \mathrm{O} \\
\mathrm{H}_{3-2 x} \mathrm{Ba}_{x} \mathrm{PMo}_{12} \mathrm{O}_{40}+x \mathrm{MSO}_{4} & \rightarrow \mathrm{H}_{3-2 x} \mathrm{M}_{x} \mathrm{PMo}_{12} \mathrm{O}_{40} \\
& +x \mathrm{BaSO}_{4} \downarrow
\end{aligned}
$$

\subsection{Characterization}

Nitrogen adsorption-desorption isotherms were obtained using a Micrometrics ASAP 2010 apparatus, after evacuation of samples at $150{ }^{\circ} \mathrm{C}$. X-ray diffraction patterns (XRD) were recorded at room temperature with a Siemens D5000 diffractometer using $\mathrm{Cu}-\mathrm{K} \alpha$ radiation $\left(\lambda=1.5418{ }^{\circ} \mathrm{A}\right)$. Infrared spectroscopy was recorded on a Fourier Transform IR Nicolet 550 apparatus, using $\mathrm{KBr}$ disks in the same conditions: $0.2 \mathrm{mg}$ of $\mathrm{MPMo}_{12}$ diluted in $200 \mathrm{mg}$ of $\mathrm{KBr}$. Diffuse reflectance UV-Vis spectra were recorded at room temperature using a Perkin-Elmer Lambda 19 spectrometer, equipped with a $60 \mathrm{~mm}$ integrating sphere coated with barium sulfate. 
Elemental analyses were carried out under an inductively coupled plasma spectrometry (ICP) measurements using a Perkin Elmer, Optima 2000 D.VS Spectrometer.

\subsection{Catalytic Reaction}

The synthesis method is based on that described in Ref. [6]. The liquid-phase oxidation of cyclohexanol (-ol), cyclohexanone (-one) or mixture of -ol and -one was carried out at $90{ }^{\circ} \mathrm{C}$, using a $100 \mathrm{~mL}$ round-bottomed flask equipped with a magnetic stirring bar and a reflux condenser. The reaction mixture is constituted by a calculated amount of catalyst and subtrate (15 mmol); where into one drop of hydrogen peroxide (30\%) was added whenever the HPS showed a colour change. The reaction time was determined to be a time in that an appropriate amount of hydrogen peroxide in the dropping funnel had been consumed that corresponds to oxidation of substrate. The reaction mixture was stirred for $14 \mathrm{~h}$ at 400 or 800 rpm. It is noteworthy that beyond $90{ }^{\circ} \mathrm{C}$, hydrogen peroxide may decompose. The resultant homogeneous mixture was cooled at $0{ }^{\circ} \mathrm{C}$ overnight. Adipic acid, one of the oxidation products, was isolated as crystals and identified by FT-IR spectroscopy and melting point $\left(151^{\circ} \mathrm{C}\right)$.

\section{Results and Discussion}

\subsection{Characterization of Catalysts}

The steochiometric coefficient determination from results of chemical analysis of salts (Table 1) was adjusted considering 12 atoms of molybdenum per Keggin unit according to the nature of HPS and was found in good agreement with the expected ones for phosphorous, molybdenum and transition element (M). The theoretical formulas of the samples were $\mathrm{FePMo}_{12} \mathrm{O}_{40}, \quad \mathrm{Co}_{1.5} \mathrm{PMo}_{12} \mathrm{O}_{40}$ and $\mathrm{Ni}_{1.5} \mathrm{PMo}_{12} \mathrm{O}_{40}$, denoted as $\mathrm{FePMo}_{12}, \mathrm{CoPMo}_{12}$ and $\mathrm{NiPMo}_{12}$, respectively.

Textural properties of $\mathrm{MPMo}_{12}$ are resumed in Table 2. Surface BET of salts are very small $\left(1-2 \mathrm{~m}^{2} / \mathrm{g}\right)$, as to that of the parent acid $\left(<10 \mathrm{~m}^{2} / \mathrm{g}\right)$. This can be attributed to the weak radius of $\mathrm{M}^{\mathrm{n}+}$ and their high solubility compared to ammonium, potassium and cesium salts. The microspores area varied between $3,010^{-2}$ and $4,710^{-2} \mathrm{~m}^{2} / \mathrm{g}$ and follows the sequence: $\mathrm{Fe}>$ $\mathrm{Co}>\mathrm{Ni}$. It is underline that the cobalt based material presents particular textural properties with higher micropore volume $\left(1,910^{-5}\right.$ against $1,710^{-5}$ and $1,210^{-5}$ $\mathrm{cm}^{3} / \mathrm{g}$ for $\mathrm{FePMo}_{12}$ and $\mathrm{NiPMo}_{12}$, respectively), higher pore volume $\left(25.010^{-4}\right.$ against $9.710^{-4}$ and $7.910^{-4}$ $\mathrm{cm}^{3} / \mathrm{g}$ for $\mathrm{FePMo}_{12}$ and $\mathrm{NiPMo}_{12}$, respectively) and also a higher average pore diameter (77.3 against 58.7 and $47.0 \AA$ for $\mathrm{NiPMo}_{12}$ and $\mathrm{FePMo}_{12}$ respectively). In all samples, the isotherms of adsorption of nitrogen are of type II and the hysteresis of type B. Then, all the studied solids are mesoporous.

In the IR spectra, the characteristic bands of the Keggin structure of heteropolyacid and $\mathrm{MPMo}_{12}$ series were observed in the low wavenumber region (1,100-500 $\mathrm{cm}^{-1}$ ) (Fig. 1). According to RocchiccioliDeltcheff, et al. [9], the bands at 1,065, 962, 865, 793

Table 1 Elemental analysis of $\mathrm{MPMo}_{12}$ series (expected values are indicated in parentheses).

\begin{tabular}{llllll}
\hline $\mathrm{MPMo}_{12}$ & Composition (P) & $(\mathrm{wt} \%) \mathrm{Mo}$ & $\mathrm{M}$ & Molar ratio (P) & $\mathrm{M}$ \\
\hline $\mathrm{FePMo}_{12}$ & 1.34 & 52.92 & 2.42 & $1.09(1)$ & $0.92(1)$ \\
$\mathrm{CoPMo}_{12}$ & 1.47 & 54.99 & 4.22 & $1.12(1)$ & $1.41(1.5)$ \\
$\mathrm{NiPMo}_{12}$ & 1.42 & 52.92 & 4.04 & $1.15(1)$ & $1.55(1.5)$ \\
\hline
\end{tabular}

Table 2 Textural properties of MPMo $\mathrm{M}_{12}$ series.

\begin{tabular}{llllll}
\hline Samples & $\begin{array}{l}S_{B E T} \\
\left(\mathrm{~m}^{2} / \mathrm{g}\right)\end{array}$ & $\begin{array}{l}\text { Microspores area } \\
\left(\mathrm{m}^{2} / \mathrm{g}\right)\end{array}$ & $\begin{array}{l}\text { Microspores volume } \\
\left(\mathrm{cm}^{3} / \mathrm{g}\right)\end{array}$ & $\begin{array}{l}\text { Pore volume } \\
\left(\mathrm{cm}^{3} / \mathrm{g}\right)\end{array}$ & $\begin{array}{l}\text { Average pore diameter } \\
(\AA)\end{array}$ \\
\hline $\mathrm{FePMo}_{12}$ & 1 & $4,710^{-2}$ & $17 \times 10^{-5}$ & $9.7 \times 10^{-4}$ & 47.0 \\
$\mathrm{NiPMo}_{12}$ & 1 & $3,010^{-2}$ & $12 \times 10^{-5}$ & $7.9 \times 10^{-4}$ & 58.7 \\
$\mathrm{CoPMo}_{12}$ & 2 & $3,810^{-2}$ & $19 \times 10^{-5}$ & $25.0 \times 10^{-4}$ & 77.3 \\
\hline
\end{tabular}




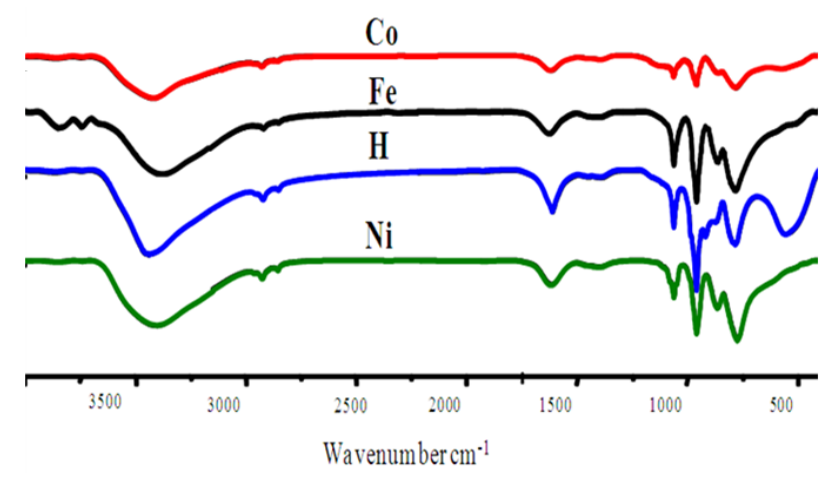

Fig. 1 FT-IR spectra of fresh MPMo $_{12}$ series.

and $561 \mathrm{~cm}^{-1}$ correspond to $v_{\mathrm{as}}\left(\mathrm{P}-\mathrm{O}_{\mathrm{a}}\right), v_{\mathrm{as}}\left(\mathrm{Mo}-\mathrm{O}_{\mathrm{d}}\right)$, $v_{\mathrm{as}}\left(\mathrm{Mo}-\mathrm{O}_{\mathrm{b}}-\mathrm{Mo}\right), v_{\mathrm{as}}\left(\mathrm{Mo}-\mathrm{O}_{\mathrm{c}}-\mathrm{Mo}\right)$ and $\delta(\mathrm{P}-\mathrm{O})$ vibrations, respectively. The comparison of the IR frequency of vibrational bands of $\mathrm{MPMo}_{12}$ salts (Table 3) with those of the parent acid $\left(\mathrm{H}_{3} \mathrm{PMo}_{12} \mathrm{O}_{40}\right)$ did not reveal significant difference within $1,500-250 \mathrm{~cm}^{-1}$ range. This suggests that primary structure remains intact and that the protons ions were replaced by the $\mathrm{M}^{\mathrm{n}+}$ ions.

In the examination of model polyoxomolybdates with well-established structures as both Keggin and Dawson anions, by diffuse reflectance spectroscopy, the only absorption band that can occur in the UV-visible range of the electronic spectra is due to the ligand-metal charge transfer (LMCT) oxygen-molybdenum (VI) [10, 11]. This type of band is usually observed between 200 and $400 \mathrm{~nm}$. In the UV-Visible spectra of as-prepared phosphomolybdate salts (Fig. 2), the bands of charge transfer from oxygen to $\mathrm{Mo}(\mathrm{VI})$ appear between 250 and $500 \mathrm{~nm}$. In addition to these bands, another band is observed in presence of $\mathrm{CoPMo}_{12}$ between 500 and $600 \mathrm{~nm}$ that can be attributed either to $\mathrm{d}-\mathrm{d}$ transition band of $\mathrm{Mo}(\mathrm{V})$ species in octahedral coordination or/and to $\mathrm{Co}$ (III) species in octahedral coordination $[4,12]$. The same observations have been made by Mazari, et al. in the presence of Co based salts of P/Mo heteropolyacid [13, 14] and in the presence of $\mathrm{Sb}$ or $\mathrm{Sn}$ based salts of P/Mo heteropolyacid [15]. This wide band can be explained by a charge transfer between molybdenum and cobalt cations as:

$$
\mathrm{Mo}(\mathrm{VI})+\mathrm{Co}(\mathrm{II}) \rightarrow \mathrm{Mo}(\mathrm{V})+\mathrm{Co}(\mathrm{III})
$$

The XRD study showed that the crystalline system of the all studied salts depends in their hydration state. Then, for high hydration level, the observed structure is cubic with Fd-3m space group similar to that of $\mathrm{H}_{3} \mathrm{PMo}_{12} \mathrm{O}_{40}, 29 \mathrm{H}_{2} \mathrm{O}$ and with a lower hydration state, the $\mathrm{XPMo}_{12}$ salts present a bad crystallinity (Fig. 3).

\subsection{Catalytic Test}

The catalytic properties of $\mathrm{FePMo}_{12}, \mathrm{CoPMo}_{12}$ and $\mathrm{NiPMo}_{12}$, Keggin-type soluble salts together with that of $\mathrm{HPMo}_{12}$ were examined in the liquid-phase oxidation of cyclohexanol (-ol), cyclohexanone (-one) and mixture of cyclohexanol (50\%) and cyclohexanone (50\%) (-ol/-one) to adipic acid (AA) in the presence of the hydrogen peroxide (30\%) under solvent-free conditions at $90{ }^{\circ} \mathrm{C}$, with $15 \mathrm{mmol}$ of subtract (in the case of mixture, $7.5 \mathrm{mmol}$ of -ol and $7.5 \mathrm{mmol}$ of -one were used). It is worth noting that in the absence of catalysts and in the presence of hydrogen peroxide, there was no adipic acid formation. On the other hand, the catalytic action of HPS is generated only by the coexistence of hydrogen peroxide. In this work, only adipic acid formation was taken into account. The other reaction products observed are the succinic and glutaric acids. Among the HPSs studied, FePMo ${ }_{12}$ has no catalytic activity toward AA whatever the nature of the substrate.

To investigate the effect of the catalyst amount on

Table 3 FT-IR vibration band wavenumbers of the MPMo ${ }_{12}$ series.

\begin{tabular}{lllll}
\hline $\mathrm{MPMo}_{12}$ & $v_{a s}\left(\mathrm{P}-\mathrm{O}_{\mathrm{a}}\right)$ & $v_{a s}\left(\mathrm{Mo}=\mathrm{O}_{\mathrm{d}}\right)$ & $v_{a s}\left(\mathrm{Mo}-\mathrm{O}_{\mathrm{b}}-\mathrm{Mo}\right)$ & $v_{a s}\left(\mathrm{Mo}-\mathrm{O}_{\mathrm{c}}-\mathrm{Mo}\right)$ \\
\hline $\mathrm{PMo}_{12}$ & 1,064 & 962 & 870 & 785 \\
$\mathrm{CoPMo}_{12}$ & 1,064 & 966 & 869 & 804 \\
$\mathrm{NiPMo}_{12}$ & 1,064 & 964 & 868 & 804 \\
$\mathrm{FePMo}_{12}$ & 1,063 & 967 & 867 & 805 \\
\hline
\end{tabular}




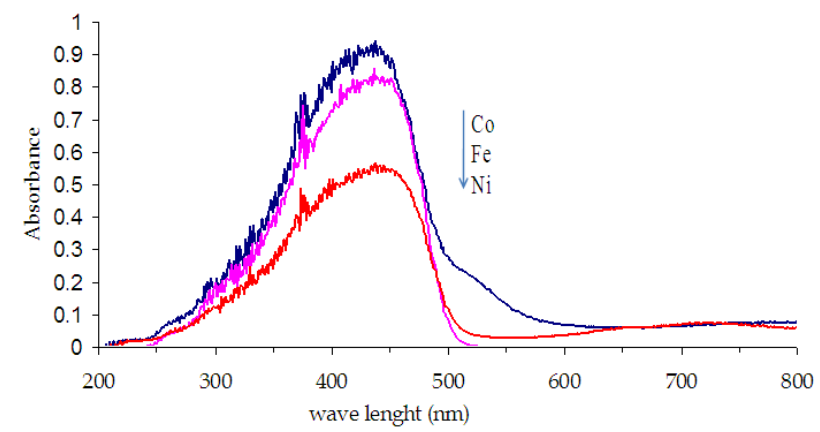

Fig. 2 UV-Vis spectra of fresh MPMo $\mathrm{M}_{12}$ series.

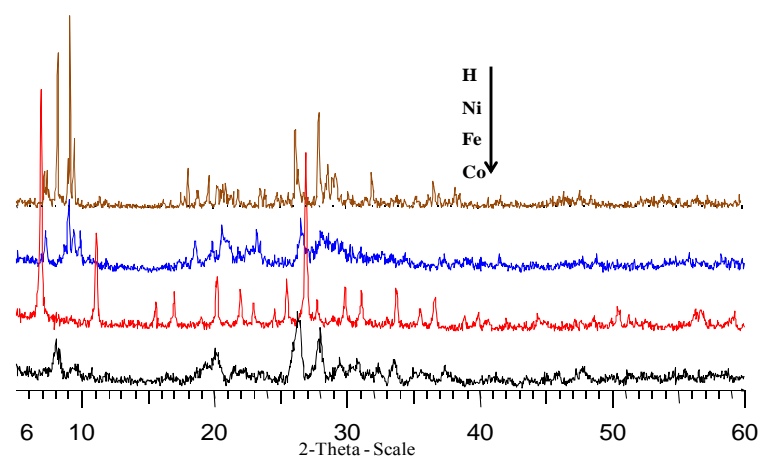

Fig. 3 XRD patterns of fresh MPMo $\mathrm{M}_{12}$ series.

the AA yield, the cyclohexanol oxidation was carried out with a stirring rate of $400 \mathrm{rpm}$ with various catalyst masses from 0.031 to $0.250 \mathrm{~g}$. The catalytic results showed that the change in the catalyst mass leads to a variation in AA yields (Table 4). With a catalyst mass of $0.031 \mathrm{~g}$, the reaction does not occur regardless of the HPS composition. The AA yield achieved $12.19 \%$ and $18.85 \%$ when the catalyst mass increases by a factor of $2(0.062 \mathrm{~g})$ and $13.15 \%$ and $19.31 \%$ when it increases by a factor of $4(0.125 \mathrm{~g})$ in the presence of $\mathrm{NiPMo}_{12}$ and $\mathrm{CoPMo}_{12}$, respectively. With a catalyst mass of $0.250 \mathrm{~g}$, the two materials behave differently with a slight increase in AA yield in the presence of $\mathrm{NiPMo}_{12}$ (14.93 against 12.19-13.15\%) and a decrease in the presence of $\mathrm{CoPMo}_{12} \quad(15.47 \%$ against $18.85 \%-19.31 \%$ ). A decrease of both cyclohexane conversion and AA selectivity with an increase of the catalyst amount was already reported with the Anderson-type catalyst. This behavior was attributed to so-called "catalyst inhibitor conversion" phenomenon [16].
Table 4 Adipic acid yield as catalyst mass function.

\begin{tabular}{lllll}
\hline POM & $\mathrm{m}_{\text {catal }}(\mathrm{g})$ & $\mathrm{m}_{\mathrm{AA}}(\mathrm{g})$ & $\mathrm{Y}_{\mathrm{AA}}(\%)$ & Time $(\mathrm{h})$ \\
\hline & 0.031 & 0.000 & 00.00 & 13 \\
$\mathrm{NiPMo}_{12}$ & 0.062 & 0.267 & 12.19 & 14 \\
& 0.125 & 0.288 & 13.15 & 41 \\
& 0.250 & 0.327 & 14.93 & 29 \\
\hline \multirow{3}{*}{$\mathrm{CoPMo}_{12}$} & 0.031 & 0.000 & 00.00 & 14 \\
& 0.062 & 0.413 & 18.85 & 14 \\
& 0.125 & 0.423 & 19.31 & 20 \\
$\mathrm{~T}_{\text {react: }} 90^{\circ} \mathrm{C} . \mathrm{n}_{\text {substrat }}=15 \mathrm{mmol}(\mathrm{V}(-\mathrm{ol})=1.63 \mathrm{ml})$. rate: $400 \mathrm{rpm}$.
\end{tabular}

When hydrogen peroxide is added at once, the AA yield is greatly reduced. Thus, it passes from $13.15 \%$ to $9.58 \%$ for a catalyst mass of $0.125 \mathrm{~g}$ in presence of $\mathrm{NiPMo}_{12}$. This observation indicates that hydrogen peroxide may be gradually added to obtain high AA yields. This method allows controlling of hydrogen peroxide consumption by observing every step of oxidation and reduction of the catalyst.

Table 5 shows catalytic activities of $\mathrm{CoPMo}_{12}$, $\mathrm{NiPMo}_{12}$ and $\mathrm{HPMo}_{12}$ in oxidation of -ol to AA at $90{ }^{\circ} \mathrm{C}$ when the reaction mixture, catalyst $(0.125 \mathrm{~g})$ and substrate $(15 \mathrm{mmol})$, was stirred for $14 \mathrm{~h}$ with stirring rate of 400 or $800 \mathrm{rpm}$. The results show the efficiency of a vigorous stirring to achieve high AA yields. Thus, the AA yield increases from $13.15 \%-19.31 \%$ to $16.87 \%-29.63 \%$ when the stirring rate increases from 400 to $800 \mathrm{rpm}$. Among the studied catalysts, $\mathrm{CoPMo}_{12}$ exhibits the highest AA yield (29.63\% against $26.50 \%$ and $16.87 \%$ for $\mathrm{NiPMo}_{12}$ and $\mathrm{HPMo}_{12}$, respectively).

The efficiency of the CoPMo $\mathrm{CM}_{12}$ salt is confirmed by the results shown in Table 6, obtained from the oxidation of -one and -ol/-one mixture. Thus, in presence of $\mathrm{CoPMo}_{12}, 31.50 \%$ and $21.14 \%$ of AA yields are obtained from -one and -ol/-one oxidation, respectively against $24.80 \%$ and $13.69 \%$ for $\mathrm{NiPMo}_{12}$ and $17.44 \%$ and $13.47 \%$ for $\mathrm{HPMo}_{12}$. On the other hand,

Table 5 Adipic acid yield as stirring rate function.

\begin{tabular}{lll}
\hline Catalyst & $Y_{A A}(\%)(400 \mathrm{rpm})$ & $Y_{A A}(\%)(800 \mathrm{rpm})$ \\
\hline $\mathrm{H}_{3} \mathrm{PMo}_{12} \mathrm{O}_{40}$ & 13.24 & 16.87 \\
$\mathrm{NiPMo}_{12} \mathrm{O}_{40}$ & 13.15 & 26.50 \\
$\mathrm{CoPMo}_{12} \mathrm{O}_{40}$ & 19.31 & 29.63 \\
\hline $\mathrm{T}_{\text {react }}: 90^{\circ} \mathrm{C} . \mathrm{m}_{\text {cat }}=0.125 \mathrm{~g} . \mathrm{n}_{\text {substrat }}=15 \mathrm{mmol}(\mathrm{V}(-\mathrm{ol})=1.63 \mathrm{ml})$.
\end{tabular}


Table 6 Adipic acid yield as substrate nature function.

\begin{tabular}{llll}
\hline Catalyst & $\begin{array}{l}Y_{A A}(\%) \\
\text { Reagent: -ol }\end{array}$ & $\begin{array}{l}Y_{A A}(\%) \\
\text { Reagent:-one }\end{array}$ & $\begin{array}{l}Y_{A A}(\%) \\
\text { Reagent: ol/-one }\end{array}$ \\
\hline $\mathrm{H}_{3} \mathrm{PMo}_{12}$ & 16.87 & 17.44 & 13.47 \\
$\mathrm{NiPMo}_{12}$ & 26.50 & 24.80 & 13.69 \\
$\mathrm{CoPMo}_{12}$ & 29.63 & 31.50 & 21.14 \\
\hline $\mathrm{T}_{\text {react }}: 90{ }^{\circ} \mathrm{C} . \mathrm{m}_{\text {cat }}=0.125 \mathrm{~g} ; \mathrm{n}_{\text {substrat }}=15 \mathrm{mmol} ;(\mathrm{V}(-\mathrm{ol})=1.63$ \\
$\mathrm{ml}$ and $\mathrm{V}($-one $)=1.58 \mathrm{ml}) ;$ rate: $800 \mathrm{rpm}$.
\end{tabular}

Table 6 shows that the AA yields obtained from the -one (17.44\%-31.50\%) are higher than those obtained from the -ol (15.29\%-21.20\%) and the (-ol/-one) mixture (13.47\%-21.14\%) regardless of the HPS composition. The high AA yields observed with the -one can be explained by the fact that the ketone is already the product of alcohol oxidation (-ol $\rightarrow$-one) and the high AA yields observed with the -ol compared to the mixture, -one/-ol, show that either the alcohol or ketone inhibits the AA synthesis. These observations have already been outlined by other authors in the AA synthesis from the -ol/-one mixture, in the presence of methylethylketone as oxidant and $\mathrm{Co} / \mathrm{Mn}$ based complexes as catalyst. The authors conclude that alcohol inhibits the oxidation of the -one [4].

The comparison of the efficacy of the three catalysts shows that the AA formation is related to oxidizing power as evidenced by the color change of initial mixture (oxidized form of the HPS) towards blue (reduced form of HPS) after the oxidation reaction of the substrate. Hydrogen peroxide acts to oxidize the reduced phase of HPS (transition from blue to the original color). The high activity observed in the case of $\mathrm{CoPMo}_{12}$ salt is due to the simultaneous presence of $\mathrm{Mo}(\mathrm{VI}) / \mathrm{Mo}(\mathrm{V})$ and $\mathrm{Co}(\mathrm{III}) / \mathrm{Co}(\mathrm{II})$ couples as observed by UV spectroscopy on the one hand, and on the other hand, the presence of Co (III) ions may contribute to the oxidation of the substrate in addition to that of Mo(VI) ions. Thus, the substrate oxidation would involve a mechanism similar to that of type Mars-van Krevelen. In this mechanism, it is admitted that during the oxidation of an alkane with molecular oxygen in the presence of metal oxide as catalyst, there is insertion of an oxygen atom from the crystal lattice to organic molecule. So, there is reduction and reoxidation of the catalyst by the molecular oxygen of the gas phase. In liquid-phase oxidation, the substrate (alcohol or ketone) consumes oxygen that would come from HPS and then the reduced HPS is oxidized by $\mathrm{H}_{2} \mathrm{O}_{2}$ by the following mechanism:

Substrate + HPS $_{\text {ox }} \rightarrow$ oxygenated products + HPS $_{\text {red }}$

$$
\mathrm{HPS}_{\text {red }}+\mathrm{H}_{2} \mathrm{O}_{2} \rightarrow \mathrm{HPS}_{\mathrm{ox}}+\mathrm{H}_{2} \mathrm{O}
$$

However, it was reported that the presence of $\mathrm{H}_{2} \mathrm{O}_{2}$, in addition to its function to oxidize the reduced POM leads to the formation of species "peroxo-POMox" intermediate species that would probably be the active species in the formation of AA $[6,17]$. The relative unstability of Keggin clusters in $\mathrm{H}_{2} \mathrm{O}_{2}$ media was already reported [18, 19].

In the case of $\mathrm{FePMo}_{12}$ salt, its inactivity in the catalytic oxidation of -ol towards adipic acid could be explained by the fact that the presence of $\mathrm{Fe}^{3+}$ ions leads either to a homolytic decomposition of $\mathrm{H}_{2} \mathrm{O}_{2}$ in the form of hydroxyl radicals $\mathrm{HO}^{\circ}$ or decomposition of $\mathrm{H}_{2} \mathrm{O}_{2}$ to $\mathrm{H}_{2} \mathrm{O}$ that acts just as that of $\mathrm{Fe}^{3+}$ ions in the Fenton reagent [20].

\section{Conclusions}

The cobalt and nickel substituted phosphomolybdates are active catalysts for cyclohexanol, cyclohexanone and cyclohexanol/cyclohexanone mixture oxidation to adipic acid under solvent-free conditions in the presence of aqueous hydrogen peroxide.

The yield of adipic acid increases significantly by increasing of stirring rate and the optimized reaction conditions are as follows: catalyst amount: $0.125 \mathrm{~g}$, stirring rate: $800 \mathrm{rpm}$ and reaction time: $14 \mathrm{~h}$.

The AA yields obtained from the -one are higher than those obtained from the -ol and the -ol/-one mixture regardless of the polyoxometalte composition. $\mathrm{CoPMo}_{12}$ exhibits the highest AA yield due to the simultaneous presence of $\mathrm{Mo}(\mathrm{VI}) / \mathrm{Mo}(\mathrm{V})$ and $\mathrm{Co}(\mathrm{III}) / \mathrm{Co}(\mathrm{II})$ redox couples.

These results pave a promising eco-friendly way for the direct oxidation of cyclohexanol, cyclohexanone 
and cyclohexanol/cyclohexanone mixture to adipic acid with Keggin-type $\mathrm{MPMo}_{12} \mathrm{O}_{40}(\mathrm{M}: \mathrm{H}, \mathrm{Co}$ and $\mathrm{Ni})$ as catalysts in presence of hydrogen peroxide.

\section{References}

[1] A. Castellan, J.C.J. Bart, S. Cavallaro, Synthesis of adipic acid via the nitric acid oxidation of cyclohexanol in a two-step batch process, Catalysis Today 9 (1991) 285-299.

[2] A. Castellan, J.C.J. Bart, S. Cavallaro, Nitric acid reaction of cyclohexanol to adipic acid, Catalysis Today 9 (1991) 255-283.

[3] F. Kapteijn, J.R. Mirasol, J.A. Moulijn, Heterogeneous catalytic decomposition of nitrous oxide, Applied Catalysis B-Environmental 9 (1996) 25-64.

[4] S.A. Chavan, D. Srinivas, P. Ratnasamy, Oxidation of cyclohexane, cyclohexanone and cyclohexanol to adipic acid by a non- $\mathrm{HNO}_{3}$ route over $\mathrm{Co} / \mathrm{Mn}$ cluster complexes, Journal of Catalysis 212 (2002) 39-45.

[5] W. Zhu, H. Li, X. He, Q. Zhang, H. Shu, Y. Yan, Synthesis of adipic acid catalyzed by surfactant-type peroxotungstates and peroxomolybdates, Catalysis Communications 9 (2008) 551-555.

[6] K. Nomiya, M. Miwa, Y. Sugaya, Catalysis by heteropolyacid VII catalytic oxidation of cyclohexanol by dodecamolybdate, Polyhedron 3 (1984) 607410.

[7] S. Ren, Z. Xie, L. Cao, X. Xie, G. Qin, J. Wang, Clean synthesis of adipic acid catalyzed by complexes derived from heteropoly acid and glycine, Catalysis Communications 10 (5) (2009) 464-467.

[8] F. Cavani, L. Ferroni, A. Frattini, C. Lucarelli, A. Mazzini, K. Raabova, et al., Evidence for the presence of alternative mechanisms in the oxidation of cyclohexanone to adipic acid with oxygen catalysed by Keggin polyoxometalates, Applied Catalysis A: General 391 (2011) 118-124.

[9] C. Rocchiccioli-Deltcheff, M. Fournier, R. Franck, R. Thouvenot, Vibrational investigations of polyxometalates: 4. Valence force fields of anions related to the lindqvist structure, Journal of Molecular Structure 114 (1984) 49-56.

[10] L. Dermeche, N. Salhi, S. Hocine, R. Thouvenot, C. Rabia, Effective Dawson type polyoxometallate catalysts for methanol oxidation, Journal of Molecular Catalysis A: Chemical 356 (2012) 29-35.
[11] F. Cavani, R. Mezzogori, A. Pigamo, F. Trifirò, E. Etienne, Main aspects of the selective oxidation of isobutane to methacrylic acid catalyzed by Keggin-type polyoxometalates, Catalysis Today 71 (2001) 97-110.

[12] T. Mazari, C.M. Roch, A. Saadi, C. Rabia, Effect of the preparation method on physicochemical and catalytic Properties of transition metal M substituted Keggin type $\mathrm{MPMo}_{12} \mathrm{O}_{40}$ heteropolyoxometalates, Studies in Surface Science and Catalysis 174 (2008) 993-996.

[13] T. Mazari, C. Roch, M.S. Hocine, N. Salhi, C. Rabia, Oxidation of propane over substituted Keggin phosphomolybdate salts, Journal of Natural Gas Chemistry 18 (2009) 319-324.

[14] T. Mazari, C. Roch, M.S. Hocine, N. Salhi, C. Rabia, Oxidation of propane over ammonium-transition metal mixed Keggin phosphomolybdate salts, Journal of Natural Gas Chemistry 19 (2010) 54-60.

[15] L. Dermeche, R. Thouvenot, S. Hocine, C. Rabia, Preparation and characterization of mixed ammonium salts of Keggin phosphomolybdate, Inorganica Chimica Acta 362 (2009) 3896-3900.

[16] H. Lü, W. Ren, P. Liu, S. Qi, W. Wang, Y. Feng, et al., One-step aerobic oxidation of cyclohexane to adipic acid using an Anderson-type catalyst $\left[\left(\mathrm{C}_{18} \mathrm{H}_{37}\right)_{2} \mathrm{~N}\left(\mathrm{CH}_{3}\right)_{2}\right]_{6} \mathrm{Mo}_{7} \mathrm{O}_{24}$, Applied Catalysis A: Gen 441-442 (2012) 136-141.

[17] N. Mizuno, C. Nozaki, I. Kiyoto, M. Misono, Highly Efficient utilization of hydrogen peroxide for selective oxygenation of alkanes catalyzed by diiron-substituted polyoxometalate precursor, Journal of the American Chemical Society 120 (1998) 9267-9272.

[18] L. Salle, J.Y. Piquemal, R. Thouvenot, C. Minot, J.M. Bregeault, Catalytic epoxidation by heteropolyoxoperoxo complexes: From novel precursors or catalysts to a mechanistic approach, Journal of Molecular Catalysis A 117 (1997) 375-387.

[19] Y. Ding, Q. Gao, G. Li, H. Zhang, J. Wang, L. Yan, et al., Selective epoxidation of cyclohexene to cyclohexene oxide catalyzed by Keggin-type heteropoly compounds using anhydrous urea-hydrogen peroxide as oxidizing reagent and acetonitrile as the solvent, Journal of Molecular Catalysis A 218 (2004) 161-170.

[20] Y. Wu, S. Qu, H. Ma, S. Ye, Catalytic behaviour of metal ions located at different sites of heteropolycompounds, Catalysis Letters 23 (1994) 195-205. 